American Journal of Applied Sciences 5 (5): 565-573, 2008

ISSN 1546-9239

(C) 2008 Science Publications

\title{
Optimal Control of the D-Policy M/G/1 Queueing System with Server Breakdowns
}

\author{
${ }^{1}$ Kuo-Hsiung Wang, ${ }^{2}$ Ching-Chang Kuo and ${ }^{3}$ Jau-Chuan Ke \\ ${ }^{1}$ Department of Applied Mathematics, National Chung-Hsing University, Taichung 402, Taiwan \\ ${ }^{2}$ Department of Industrial Engineering and Management, National Chiao Tung University, \\ Hsin Chu 30050, Taiwan \\ ${ }^{3}$ Department of Applied Statistics, National Taichung Institute of Technology, Taichung 404, Taiwan
}

\begin{abstract}
This study deals with a single server in the D-policy M/G/1 queueing system in which the server is turned off at the end of each complete period and is activated again only when the cumulative completion times of the customers in the system exceeds a given level $\mathrm{D}$. While the server is working, he is subject to breakdowns according to a Poisson process. When the server breaks down, he requires repair at a repair facility, where the repair time obeys a general distribution. We have demonstrated that the probability that the server is busy in the steady-state is equal to the traffic intensity. The total expected cost function per customer per unit time is constructed to determine the optimal operating D-policy at a minimum cost. We use the steady-state analytic results and apply an efficient Matlab computer program to calculate the optimal value of D. Based on three different service distributions: exponential, 3-stage Erlang and deterministic, we provide extensive numerical computation for illustration purpose. Sensitivity analysis is also investigated.
\end{abstract}

Key words: Analytic results, breakdowns, general repair time, general service time, optimal policy, sensitivity analysis

\section{INTRODUCTION}

In this study, we deal with the optimal operation of a single non-reliable sever in an $\mathrm{M} / \mathrm{G} / 1$ queueing system operating under the D-policy, i.e., the server is turned off at the end of each complete period (busy period plus breakdown period) and is turned on when the sum of the completion times of all waiting customers exceeds the fixed value D. A non-reliable server means that the server is typically subject to unpredictable breakdowns. It is assumed that the breakdown times of the server follow the negative exponential distribution and the repair times of the server obey a general distribution.

One example of an application fitting our model is the following central mail handling system. Mail is collected from mailboxes with fixed pick-up times and then is sent to the central mail handling office. The workers at the central mail handling office sorts the parcels into categories including registered mail, ordinary mail in a long flat envelope and ordinary mail in a standard envelope. Sorted mail forms a waiting line according to a random process. When the workload of sorted mail exceeds $\mathrm{D}$, the automated distribution machine is turned on and starts dispensing the parcels into slots according to the destination post office. In addition, the machine may be broken down when it is working. When the automated distribution machine fails, it is emergently repaired. As soon as the repair is completed, the automated distribution machine immediately servers the waiting sorted mail until the processed workload becomes zero. Another application of this model is in the study of PCB Surface Mount process. Consider a PCB Surface Mount system. Assume that PCB arrives according to a random process. Because of the cost involved in setup machine, it is desirable that the reflow machine begins operating whenever the workload of PCB reaches a critical value D. The reflow process may be interrupted when machine encounters unpredicted breakdowns. When reflow interruptions occur (breakdowns), it is emergently recovered with a random time.

It is assumed that customers arrive following a Poisson process with parameter $\lambda$ and the service times of the customers are independent and identically distributed (i.i.d.) random variables having a distribution function $F_{S}(t)$, a probability density function $\mathrm{f}_{\mathrm{S}}(\mathrm{t})$ and a finite $\mathrm{kth}$ moment $\mu_{\mathrm{k}}=\mathrm{E}\left[\mathrm{S}^{\mathrm{k}}\right](\mathrm{k}=1$,

Corresponding Author: Kuo-Hsiung Wang, Department of Applied Mathematics, National Chung-Hsing University, Taichung 402, Taiwan Tel: +886-4-22860133/509 Fax: +886-4-22873028 
2, 3). Let $\overline{\mathrm{f}}_{\mathrm{S}}(\mathrm{s})$ denote the Laplace-Stieltjes transform (abbreviated LST) of a function $\mathrm{f}_{\mathrm{S}}(\mathrm{t})$. It is assumed that the server can break down at any time with a Poisson breakdown intensity $\alpha$. Whenever the server breaks down, he is immediately repaired in a repair facility, where the repair times are independent and identically distributed random variables having a distribution function $F_{R}(t)$, a probability density function $f_{R}(t)$ and a finite kth moment $\beta_{\mathrm{k}}=\mathrm{E}\left[\mathrm{R}^{\mathrm{k}}\right](\mathrm{k}=1,2,3)$. Let $\overline{\mathrm{f}}_{\mathrm{R}}(\mathrm{s})$ denote the LST of a function $f_{R}(t)$. Service is allowed to be interrupted if the server breaks down. The server immediately starts repair and once the server is repaired he immediately returns to serve customers until the system becomes empty.

The controllable M/G/1 queueing system has been extensively investigated in the open literature. Balachandran $^{[1]}$ first introduced the concept of a Dpolicy which turns the server off when the system is empty and turned the server on when the cumulative service times of the customers in the system exceed a given threshold of size $D$. The D-policy M/G/1 queueing system with a reliable server was analyzed by Balachandran ${ }^{[1]}$, Balachandran and Tijms ${ }^{[2]}$, Gakis et al. ${ }^{[3]}$ and many others. Balachandran and Tijms $^{[2]}$ developed the optimal D-policy when the cost function is based on the expected number of customers in the system. Gakis et al. ${ }^{[3]}$ demonstrated that the probability that the server is busy in the steady-state is equal to the traffic intensity. $\mathrm{Li}$ and $\mathrm{Niu}^{[4]}$ developed the waiting distribution (in queue) of customers in the more general GI/G/1 queue with D-policy. For an M/G/1 queueing system operating under the D-policy, Sivazlian $^{[5]}$ derived an explicit approximate expression for the optimal value of $\mathrm{D}$.

The first objective of this paper is to derive the steady-state analytic results, such as the expected length of the complete, busy, breakdown and idle periods, the expected length of the busy cycle and the probability that the server is busy. We show that the probability that the server is busy is equal to traffic intensity $\rho$. The second objective of the paper is to formulate the system's total expected cost in order to determine the optimal operating D-policy at the minimum cost. The steady-state analytic results and an efficient Matlab computer program are used to calculate the optimal value of $\mathrm{D}$. The final objective of the paper is to present extensive numerical computation for three different service distributions such as exponential, 3-stage Erlang and deterministic, to illustrate sensitivity investigation.

\section{THE ORDINARY M/G/1 QUEUEING SYSTEM WITH SERVER BREAKDOWNS}

First three moments of the completion time distribution: Let $\mathrm{H}$ be a random variable representing the completion time of a customer, which includes both the service time of a customer and the repair time of a server, in the ordinary M/G/1 queueing system with server breakdowns.

Let $\overline{\mathrm{f}}_{\mathrm{H}}(\mathrm{s})$ denote the LST of completion time $\mathrm{H}$. Thus $\overline{\mathrm{f}}_{\mathrm{H}}(\mathrm{s})$ is given by:

$$
\overline{\mathrm{f}}_{\mathrm{H}}(\mathrm{s})=\overline{\mathrm{f}}_{\mathrm{s}}\left[\mathrm{s}+\alpha-\alpha \overline{\mathrm{f}}_{\mathrm{R}}(\mathrm{s})\right]
$$

where $\bar{f}_{S}(s)$ and $\bar{f}_{R}(s)$ denote the LST of service time and repair time, respectively and $\alpha$ denotes the breakdown rate. The derivation of (1) is given in Wang and $\mathrm{Ke}^{[7]}$. It follows from (1) that the first three moments of the completion time distribution are given by:

$$
\begin{gathered}
\theta_{1}=\mathrm{E}[\mathrm{H}]=-\left.\frac{\mathrm{d}}{\mathrm{ds}}\left[\overline{\mathrm{f}}_{\mathrm{H}}(\mathrm{s})\right]\right|_{\mathrm{s}=0}=\mu_{1}\left(1+\alpha \beta_{1}\right) \\
\theta_{2}=\mathrm{E}\left[\mathrm{H}^{2}\right]=\left.\frac{\mathrm{d}^{2}}{\mathrm{ds}^{2}}\left[\overline{\mathrm{f}}_{\mathrm{H}}(\mathrm{s})\right]\right|_{\mathrm{s}=0}=\mu_{2}\left(1+\alpha \beta_{1}\right)^{2}+\mu_{1} \alpha \beta_{2} \\
\theta_{3}=\mathrm{E}\left[\mathrm{H}^{3}\right]=-\left.\frac{\mathrm{d}^{3}}{\mathrm{ds}^{3}}\left[\overline{\mathrm{f}}_{\mathrm{H}}(\mathrm{s})\right]\right|_{\mathrm{s}=0}=\mu_{3}\left(1+\alpha \beta_{1}\right)^{3} \\
+3 \mu_{2} \alpha \beta_{2}\left(1+\alpha \beta_{1}\right)-\mu_{1} \alpha \beta_{3},
\end{gathered}
$$

and

$$
\rho_{\mathrm{H}}=\lambda \theta_{1}=\rho\left(1+\alpha \beta_{1}\right)
$$

where $\rho=\lambda \mu_{1}$. The traffic intensity $\rho_{\mathrm{H}}$ is assumed to be less than unity.

Expected length of the complete period, the busy period and the breakdown period: The busy period is initiated when the customer arrives in the system and the server begins for service. During the busy period, the server may break down and starts his repair immediately. This is called the breakdown period. The server is turned off when the system becomes empty. This is called the idle period. Since the complete period starts when the idle period terminates, the complete period is represented by the sum of the busy period and the breakdown period. 
From the results of Wang and $\mathrm{Ke}^{[7]}$, the LST of the distribution of the complete period for the ordinary $\mathrm{M} / \mathrm{G} / 1$ queueing system with server breakdowns is given by:

$$
\overline{\mathrm{f}}_{\mathrm{H}_{0}}(\mathrm{~s})=\overline{\mathrm{f}}_{\mathrm{H}}\left[\mathrm{s}+\lambda-\lambda \overline{\mathrm{f}}_{\mathrm{H}_{0}}(\mathrm{~s})\right]
$$

Using (1-3) and (6), the first two moments of the complete period are given by:

$$
\begin{array}{r}
\mathrm{E}\left[\mathrm{H}_{0}\right]=\frac{\mu_{1}\left(1+\alpha \beta_{1}\right)}{1-\rho\left(1+\alpha \beta_{1}\right)}=\frac{\theta_{1}}{1-\rho_{\mathrm{H}}} \\
\mathrm{E}\left[\mathrm{H}_{0}^{2}\right]=\frac{\mu_{2}\left(1+\alpha \beta_{1}\right)^{2}+\mu_{1} \alpha \beta_{2}}{\left[1-\rho\left(1+\alpha \beta_{1}\right)\right]^{3}}=\frac{\theta_{2}}{\left(1-\rho_{\mathrm{H}}\right)^{3}}
\end{array}
$$

We denote by $E\left[\mathrm{~B}_{0}\right]$ and $\mathrm{E}\left[\mathrm{D}_{0}\right]$ the expected length of the busy period and the breakdown period, respectively. We shall use the following known formulas, which can be found in Wang and $\mathrm{Ke}^{[7]}$ :

$$
\begin{array}{r}
E\left[B_{0}\right]=\frac{\mu_{1}}{1-\rho_{\mathrm{H}}} \\
\mathrm{E}\left[\mathrm{D}_{0}\right]=\frac{\mu_{1} \alpha \beta_{1}}{1-\rho_{\mathrm{H}}} .
\end{array}
$$

\section{THE D POLICY M/G/1 QUEUEING SYSTEM WITH SERVER BREAKDOWNS}

Expected length of the complete period, the busy period and the breakdown period: The server is turned off (idle) at the end of each complete period and is activated again only when the cumulative workload (the cumulative completion times of the customers in the system) firstly exceeds the fixed value $D$. Let $R_{D}$ be the forward recurrent time of the ordinary renewal process $X_{t}$ at epoch $t=D$. Thus the total workload when a complete period is initiated is $\mathrm{D}+\mathrm{R}_{\mathrm{D}}$. Applying the expression (58) of Gakis et al. ${ }^{[3]}$ (p. 57), we get:

- $0 \leq \mathrm{x} \leq \mathrm{D}$

$$
\mathrm{f}_{\mathrm{H}_{\mathrm{D}}}(\mathrm{x})=0,
$$

- $\mathrm{D} \leq \mathrm{x}<\infty$

$$
\begin{aligned}
& f_{H_{D}}(x)=e^{-\lambda x} f_{R_{D}}(x-D)+ \\
& \int_{D}^{x} f_{R_{D}}(y-D) \sum_{n=1}^{\infty} f_{H_{0}}^{*(n)}(x-y) \frac{(\lambda y)^{n} e^{-\lambda y}}{n !} d y .
\end{aligned}
$$

Note that the expression for $\mathrm{f}_{\mathrm{H}_{\mathrm{D}}}(\mathrm{x})$ is obtained only by replacing busy period by completion period $\mathrm{H}_{0}$ in the formula of the $D$ policy $M / G / 1$ queueing system with server breakdowns.

Taking the LST of $\mathrm{f}_{\mathrm{H}_{\mathrm{D}}}(\mathrm{x})$, we have:

$$
\begin{gathered}
\bar{f}_{H_{D}}(s)=\int_{D}^{\infty} e^{-(\lambda+s) x} f_{R_{D}}(x-D) d x \\
+\int_{D}^{\infty} e^{-s x} \int_{D}^{x} f_{R_{D}}(y-D) \sum_{n=1}^{\infty} f_{H_{0}}^{*(n)}(x-y) \frac{(\lambda y)^{n} e^{-\lambda y}}{n !} d y d x .
\end{gathered}
$$

Changing the order of integration of (11) and changing the variables of integration, it finally yields

$$
\overline{\mathrm{f}}_{\mathrm{H}_{\mathrm{D}}}(\mathrm{s})=\mathrm{e}^{-\left[\lambda+\mathrm{s}-\lambda \overline{\mathrm{f}_{\mathrm{H}_{0}}}(\mathrm{~s})\right] \mathrm{D}} \overline{\mathrm{f}}_{\mathrm{R}_{\mathrm{D}}}\left[\lambda+\mathrm{s}-\lambda \overline{\mathrm{f}}_{\mathrm{H}_{0}}(\mathrm{~s})\right] .
$$

Let $E\left[H_{D}\right]$ be the expected length of the complete period for the D policy M/G/1 queueing system with server breakdowns. Using (12), we get:

$$
\begin{aligned}
& \mathrm{E}\left[\mathrm{H}_{\mathrm{D}}\right]=-\frac{\mathrm{d}}{\mathrm{ds}}\left[\overline{\mathrm{f}}_{\mathrm{H}_{\mathrm{D}}}(\mathrm{s})\right]_{\mathrm{s}=0} \\
& \quad=\left(1+\lambda \mathrm{E}\left[\mathrm{H}_{0}\right]\right)\left(\mathrm{D}+\mathrm{E}\left[\mathrm{R}_{\mathrm{D}}\right]\right),
\end{aligned}
$$

where $\mathrm{E}\left[\mathrm{H}_{0}\right]$ is given in (7). We note from (7) that:

$$
\begin{aligned}
& 1+\lambda \mathrm{E}\left[\mathrm{H}_{0}\right]=1+\lambda \frac{\mu_{1}\left(1+\alpha \beta_{1}\right)}{1-\rho_{\mathrm{H}}} \\
& =\frac{1}{1-\rho_{\mathrm{H}}}=\frac{1}{\theta_{1}} \times \frac{\theta_{1}}{1-\rho_{\mathrm{H}}}=\frac{\mathrm{E}\left[\mathrm{H}_{0}\right]}{\theta_{1}}
\end{aligned}
$$
we have

Following the result of Balachandran and Tijms ${ }^{[2]}$,

$$
\mathrm{D}+\mathrm{E}\left[\mathrm{R}_{\mathrm{D}}\right]=\theta_{1}\left[1+\mathrm{M}_{\mathrm{H}}(\mathrm{D})\right]
$$

Here, $M_{H}(D)$ is the renewal function

$$
\mathrm{M}_{\mathrm{H}}(\mathrm{D})=\sum_{\mathrm{n}=1}^{\infty} \mathrm{F}_{\mathrm{H}}^{(\mathrm{n})}(\mathrm{D})
$$

where, $\mathrm{F}_{\mathrm{H}}^{(\mathrm{n})}(\mathrm{D})$ is the $n$-fold convolution of $\mathrm{F}$ with itself.

Substituting (14) and (15) into (13), we obtain:

$$
\mathrm{E}\left[\mathrm{H}_{\mathrm{D}}\right]=\mathrm{E}\left[\mathrm{H}_{0}\right]\left[1+\mathrm{M}_{\mathrm{H}}(\mathrm{D})\right]
$$

We denote by $E\left[B_{D}\right]$ and $E\left[D_{D}\right]$ the expected length of the busy period and the breakdown period, respectively. We obtain: 


$$
E\left[H_{D}\right]=E\left[B_{D}\right]+E\left[D_{D}\right]
$$

Recall that $\mathrm{E}\left[\mathrm{H}_{0}\right]=\mathrm{E}\left[\mathrm{B}_{0}\right]+\mathrm{E}\left[\mathrm{D}_{0}\right]$. It implies from (9), (10), (17) that:

$$
\begin{array}{r}
E\left[B_{D}\right]=E\left[B_{0}\right]\left[1+M_{H}(D)\right]=\frac{\mu_{1}\left[1+M_{H}(D)\right]}{1-\rho_{H}} \\
E\left[D_{D}\right]=E\left[D_{0}\right]\left[1+M_{H}(D)\right]=\frac{\mu_{1} \alpha \beta_{1}\left[1+M_{H}(D)\right]}{1-\rho_{H}}
\end{array}
$$

Expected length of the busy cycle: The busy cycle for the $\mathrm{D}$ policy $\mathrm{M} / \mathrm{G} / 1$ queueing system with server breakdowns, denoted by $\mathrm{C}_{\mathrm{D}}$, is the length of time from the beginning of the last idle period to the beginning of the next idle period. Since the busy cycle is the sum of the idle period and the complete period, we obtain:

$$
\mathrm{E}\left[\mathrm{C}_{\mathrm{D}}\right]=\mathrm{E}\left[\mathrm{I}_{\mathrm{D}}\right]+\mathrm{E}\left[\mathrm{H}_{\mathrm{D}}\right]
$$

We must now find $E[I / D]$. Following the terminating of an idle period, the server returns to the system to initiate a complete period, if the cumulative amount of workload firstly exceeds D. The idle period is denoted by the sum of $\mathrm{K}$ idle periods in the ordinary $\mathrm{M} / \mathrm{G} / 1$ queueing system with server breakdowns where $\mathrm{K}$ satisfies the following condition:

$$
\mathrm{K}=\min \left\{\mathrm{n} \mid \mathrm{H}_{1}+\mathrm{H}_{2}+\ldots, \mathrm{H}_{\mathrm{n}} \geq \mathrm{D}\right\}
$$

where $\mathrm{H}_{\mathrm{i}}, \mathrm{i}=1,2, \ldots, \mathrm{n}$ denotes the completion times. Let $\mathrm{f}_{\mathrm{I}_{\mathrm{D}}}(\mathrm{x} \mid \mathrm{K}=\mathrm{n})$ be defined as the conditional probability density function of the idle period given $\mathrm{K}=\mathrm{n}$. Thus, we obtain:

$$
\mathrm{f}_{\mathrm{I}_{\mathrm{D}}}(\mathrm{x} . \mathrm{K}=\mathrm{n})=\mathrm{f}_{\mathrm{I}_{0}}^{*(\mathrm{n})}(\mathrm{x}), \mathrm{n}=1,2, \ldots
$$

We note that:

$\mathrm{P}\{\mathrm{K}=\mathrm{n}\}=\mathrm{P}\{\mathrm{X}(\mathrm{D})=\mathrm{n}-1\}=\mathrm{F}_{\mathrm{H}}^{(\mathrm{n}-1)}(\mathrm{D})-\mathrm{F}_{\mathrm{H}}^{(\mathrm{n})}(\mathrm{D})$. It implies from (21) that:

$$
\begin{aligned}
& f_{I_{D}}(x)=\sum_{n=1}^{\infty} f_{I_{D}}(x \mid K=n) P\{K=n\} \\
& =\sum_{n=1}^{\infty} f_{I_{0}}^{*(n)}(x)\left[F_{H}^{(n-1)}(D)-F_{H}^{(n)}(D)\right] .
\end{aligned}
$$

Taking the LST on both side of (22) yields:

$$
\bar{f}_{I_{D}}(s)=\sum_{n=1}^{\infty}\left[\bar{f}_{\mathrm{I}_{0}}(s)\right]^{n}\left[F_{H}^{(n-1)}(D)-F_{H}^{(n)}(D)\right]
$$

The expected length of the idle period, E[I/D], for the $\mathrm{D}$ policy $\mathrm{M} / \mathrm{G} / 1$ queueing system with server breakdowns is obtained by using (23):

$$
\begin{aligned}
\mathrm{E}\left[\mathrm{I}_{\mathrm{D}}\right] & =\mathrm{E}\left[\mathrm{I}_{0}\right] \sum_{\mathrm{n}=1}^{\infty} \mathrm{n}\left[\mathrm{F}_{\mathrm{H}}^{(\mathrm{n}-1)}(\mathrm{D})-\mathrm{F}_{\mathrm{H}}^{(\mathrm{n})}(\mathrm{D})\right] \\
& =\mathrm{E}\left[\mathrm{I}_{0}\right] \sum_{\mathrm{n}=0}^{\infty} \mathrm{F}_{\mathrm{H}}^{(\mathrm{n})}(\mathrm{D}) \\
& =\mathrm{E}\left[\mathrm{I}_{0}\right]\left[1+\mathrm{M}_{\mathrm{H}}(\mathrm{D})\right]
\end{aligned}
$$

where $E\left[I_{0}\right]=1 / \lambda, M_{H}(D)=\sum_{n=1}^{\infty} F_{H}^{(n)}(D)$ and $F_{H}^{(0)}(D)$ is defined to be 1 .

Substituting (17) and (24) into (20) yields $\mathrm{E}\left[\mathrm{C}_{\mathrm{D}}\right]=\left(\mathrm{E}\left[\mathrm{I}_{0}\right]+\mathrm{E}\left[\mathrm{H}_{0}\right]\right)\left[1+\mathrm{M}_{\mathrm{H}}(\mathrm{D})\right]$.

From (1), (4) and (7), we get:

$$
E\left[C_{D}\right]=\frac{1+M_{H}(D)}{\lambda\left(1-\rho_{H}\right)}
$$

Probability that the server is busy: In steady state, the probability that the server is busy in the D policy M/G/1 queueing system with server breakdowns, denoted by $\mathrm{P}_{\mathrm{B}_{\mathrm{D}}}$ is the proportion of time the server is busy, that is,

$$
\mathrm{P}_{\mathrm{B}_{\mathrm{D}}}=\frac{\mathrm{E}\left[\mathrm{B}_{\mathrm{D}}\right]}{\mathrm{E}\left[\mathrm{C}_{\mathrm{D}}\right]}
$$

Substituting $E\left[B_{D}\right]$ in (18) and $E\left[C_{D}\right]$ in (25) into (26) yields:

$$
\mathrm{P}_{\mathrm{B}_{\mathrm{D}}}=\lambda \mu_{1}=\rho
$$

On the D-policy M/G/1 queueing system with server breakdowns, we prove that the probability that the server is busy in the steady-state is equal to the traffic intensity.

\section{OPTIMAL DESIGN OF THE D POLICY}

Expected number of customers in the system: Applying the known formula for the expected number of customers in the D policy M/G/1 queueing system with a reliable server, we obtain the following expected number of customers in the D policy M/G/1 queueing system with server breakdowns

$$
L_{D}=D+\frac{\lambda \theta_{D}}{2\left(1-\rho_{H}\right)}-\frac{D+\int_{0}^{D} M_{H}(y) d y}{1+M_{H}(D)}
$$


We note that expression (28) is obtained only by replacing service times by completion times in the formula of the D policy M/G/1 queueing system with reliable server $\left(\mathrm{Tijms}^{[6]}\right.$ )

Determining the optimal policy: We develop the average total expected cost per unit time for the D policy M/G/1 queueing system with server breakdowns in which $\mathrm{D}$ is a decision variable. Our objective is to determine the optimum value of the control parameter $\mathrm{D}$, say D* at minimum cost.

The operating cost and the breakdown cost for the server are neglected because $E\left[B_{D}\right] / E\left[C_{D}\right]$ and $E\left[D_{D}\right] / D\left[C_{D}\right]$ are not functions of the decision variable D. Let:

$R_{1}\left(R_{2}\right) \equiv$ fixed cost for turning the server on (off); we put $\mathrm{R}=\mathrm{R}_{1}+\mathrm{R}_{2}$;

$\mathrm{h} \equiv$ holding cost per unit time for each customer present in the system.

Then, applying the results of Balachandran and Tijms $^{[2]}$ (or Tijms ${ }^{[6]}$ ), the minimum average total expected cost per unit time for the D policy M/G/1 queueing system with server breakdowns is given by:

$$
\begin{aligned}
& F(D)=R \frac{1}{E\left[C_{D}\right]}+h L_{D}=R \frac{\lambda\left(1-\rho_{H}\right)}{1+M_{H}(D)} \\
& +h\left[D+\frac{\lambda \theta_{2}}{2\left(1-\rho_{H}\right)}-\frac{D+\int_{0}^{D} M_{H}(y) d y}{1+M_{H}(D)}\right] .
\end{aligned}
$$

It is easy to show that $F(D)$ is minimal for the unique solution $\mathrm{D}^{*}$ satisfying

$$
\begin{aligned}
\int_{0}^{D^{*}} & {\left[1+M_{H}(y)\right] d y=D^{*}+\int_{0}^{D^{*}} M_{H}(y) d y } \\
= & \frac{R \lambda\left(1-\rho_{H}\right)}{H}
\end{aligned}
$$

Substituting $D^{*}$ into (29), we obtain the minimum average expected cost per unit time for the D policy M/G/1 queue with server breakdowns as:

$$
\mathrm{F}(\mathrm{D})=\mathrm{HD}^{*}+\frac{\mathrm{H} \lambda \theta_{2}}{2\left(1-\rho_{\mathrm{H}}\right)}
$$

Approximate solution for the optimal D level: We now develop the asymptotic expansions as follows. Suppose that D is sufficiently large compared with $\theta_{1}$. Following the results of Tijms ${ }^{[6]}$, we get:

$$
\mathrm{E}\left(\mathrm{R}_{\mathrm{D}}\right) \approx \frac{\theta_{2}}{2 \theta_{1}} \text { and } \mathrm{E}\left(\mathrm{R}_{\mathrm{D}}^{2}\right) \approx \frac{\theta_{3}}{3 \theta_{1}}
$$

which is independent of $\mathrm{D}$. We assume that $\theta_{3}<\infty$. It yields from (16) and (32) that:

$$
\begin{aligned}
& \mathrm{M}_{\mathrm{H}}(\mathrm{D})=\frac{\mathrm{D}+\mathrm{E}\left[\mathrm{R}_{\mathrm{D}}\right]}{\theta_{1}}-1 \\
& \approx \frac{\mathrm{D}}{\theta_{1}}+\frac{\theta_{2}}{2 \theta_{1}^{2}}-1 .
\end{aligned}
$$

It follows from (32) and (33) that:

$$
\begin{aligned}
& \int_{0}^{\mathrm{D}} \mathrm{M}_{\mathrm{H}}(\mathrm{y}) \mathrm{dy} » \int_{0}^{\mathrm{D}}\left[\frac{\mathrm{y}}{\mathrm{q}_{1}}+\frac{\mathrm{q}_{2}}{2 \mathrm{q}_{1}^{2}}-1\right] d y \\
\approx & \frac{\mathrm{D}^{2}}{2 \theta_{1}}+\mathrm{D}\left[\frac{\theta_{2}}{2 \theta_{1}^{2}}-1\right]+\frac{\theta_{2}^{2}}{4 \theta_{1}^{3}}-\frac{\theta_{3}}{6 \theta_{1}^{2}} .
\end{aligned}
$$

Substituting the asymptotic expansion (34) into (29), we obtain that for the D policy M/G/1 queueing system with server breakdowns, the average total expected cost per unit time is approximated by:

$$
\begin{aligned}
& \mathrm{F}(\mathrm{D}) \approx\left(\frac{\mathrm{D}}{\theta_{1}}+\frac{\theta_{2}}{2 \theta_{1}^{2}}\right)^{-1}\left[\begin{array}{l}
\mathrm{R} \lambda\left(1-\rho_{\mathrm{H}}\right)-\frac{\mathrm{h}}{2} \\
\left(\frac{\mathrm{D}^{2}}{\theta_{1}}+\frac{\mathrm{D} \theta_{2}}{\theta_{1}^{2}}+\frac{\theta_{2}^{2}}{2 \theta_{1}^{3}}-\frac{\theta_{3}}{3 \theta_{1}^{2}}\right)
\end{array}\right] \\
& +\mathrm{hD}+\frac{\mathrm{h} \lambda \theta_{2}}{2\left(1-\rho_{\mathrm{H}}\right)} \text {. }
\end{aligned}
$$

Setting $d F(D) / d D=0$ yields

$$
\mathrm{D}^{*} \approx-\frac{\theta_{2}}{2 \theta_{1}}+\frac{\theta_{2}}{\theta_{1}} \sqrt{\frac{2 \mathrm{R} \lambda\left(1-\rho_{\mathrm{H}}\right) \theta_{1}^{3}}{\mathrm{~h} \theta_{2}^{2}}+\frac{\theta_{1} \theta_{3}}{3 \theta_{2}^{2}}-\frac{1}{4}} .
$$

Since

$$
\frac{\mathrm{d}^{2} \mathrm{~F}(\mathrm{D})}{\mathrm{dD}^{2}}>0
$$

thus $D^{*}$ is the unique minimizer of $F(D)$.

Special cases: We consider three special cases for three different service time and repair time distributions such as exponential (M), k-stage Erlang $\left(\mathrm{E}_{\mathrm{k}}\right)$ and deterministic (D). The explicit expressions for the $\theta i(i=1,2,3)$ for three different service time and repair time distributions such as exponential, k-stage Erlang and deterministic are listed as follows.

Case 1: The service time and repair time have exponential distribution. Let $\mu_{\mathrm{i}}$ and $\beta \mathrm{i}(\mathrm{i}=1,2,3)$ be the 
first three moments of the service time and repair time distributions. In this case, we have $\mu_{1}=1 / \mu, \mu_{2}=2 / \mu^{2}$, $\mu_{3}=6 / \mu^{3}$ and $\beta 1=1 / \beta, \beta_{2}=2 / \beta^{2}, \beta_{3}=6 / \beta^{3}$.

It implies from (1-3) that:

$$
\begin{gathered}
\theta_{1}=\frac{1}{\mu}\left(1+\frac{\alpha}{\beta}\right) \\
\theta_{2}=\frac{2}{\mu^{2}}\left(1+\frac{\alpha}{\beta}\right)^{2}+\frac{2 \alpha}{\mu \beta^{2}} \\
\theta_{3}=\frac{6}{\mu^{3}}\left(1+\frac{\alpha}{\beta}\right)^{3}+\frac{12 \alpha}{\mu^{2} \beta^{2}}\left(1+\frac{\alpha}{\beta}\right)-\frac{6 \alpha}{\mu \beta^{3}}
\end{gathered}
$$

Substituting $\theta_{\mathrm{i}}(\mathrm{i}=1,2,3)$ into formula (36) and using (4), we obtain the approximate optimal value $D^{*}$ for the exponential service and repair times.

Case 2: The service time has k-stage Erlang distribution and the repair time has $\mathrm{m}$-stage Erlang distribution. In this case, we have $\mu_{1}=1 / \mu, \mu_{2}=$ $(\mathrm{k}+1) / \mathrm{k} \mu^{2}, \mu^{3}=(\mathrm{k}+1)(\mathrm{k}+2) / \mathrm{k}^{2} \mu^{3}$ and $\beta_{1}=1 / \beta, \beta_{2}=$ $(\mathrm{m}+1) / \mathrm{m} \beta^{2}, \beta_{3}=(\mathrm{m}+1)(\mathrm{m}+2) / \mathrm{m}^{2} \beta^{3}$.

Again, it follows from (1)-(3) that:

$$
\begin{gathered}
\theta_{1}=\frac{1}{\mu}\left(1+\frac{\alpha}{\beta}\right) \\
\theta_{2}=\frac{\mathrm{k}+1}{\mathrm{k} \mu^{2}}\left(1+\frac{\alpha}{\beta}\right)^{2}+\frac{(\mathrm{m}+1) \alpha}{\mathrm{m} \mu \beta^{2}} \\
\theta_{3}=\frac{(\mathrm{k}+1)(\mathrm{k}+2)}{\mathrm{k}^{2} \mu^{3}}\left(1+\frac{\alpha}{\beta}\right)^{3} \\
+\frac{3(\mathrm{k}+1)(\mathrm{m}+1) \alpha}{\mathrm{km} \mu^{2} \beta^{2}}\left(1+\frac{\alpha}{\beta}\right)-\frac{(\mathrm{m}+1)(\mathrm{m}+2) \alpha}{\mathrm{m}^{2} \mu \beta^{3}}
\end{gathered}
$$

Similarly, substituting $\theta_{\mathrm{i}}(\mathrm{i}=1,2,3)$ into formula (36) and using (4), we get the approximate optimal value $D^{*}$ for the $\mathrm{k}$-stage Erlang service time and $\mathrm{m}$ stage Erlang repair time.

Case 3: The service time and repair time have constant distribution. In this case, we have $\mu_{1}=1 / \mu, \mu_{2}=1 / \mu^{2}$, $\mu^{3}=1 / \mu^{3}$ and $\beta_{1}=1 / \beta, \beta_{2}=1 / \beta^{2}, \beta_{3}=1 / \beta^{3}$.

It yields from (1-3) that:

$$
\theta_{1}=\frac{1}{\mu}\left(1+\frac{\alpha}{\beta}\right)
$$

$$
\begin{gathered}
\theta_{2}=\frac{1}{\mu^{2}}\left(1+\frac{\alpha}{\beta}\right)^{2}+\frac{\alpha}{\mu \beta^{2}} \\
\theta_{3}=\frac{1}{\mu^{3}}\left(1+\frac{\alpha}{\beta}\right)^{3}+\frac{3 \alpha}{\mu^{2} \beta^{2}}\left(1+\frac{\alpha}{\beta}\right)-\frac{\alpha}{\mu \beta^{3}}
\end{gathered}
$$

Substituting $\theta_{\mathrm{i}}(\mathrm{i}=1,2,3)$ into formula (36) and using (4) again, we have the approximate optimal value $\mathrm{D}^{*}$ for the constant service and repair times.

\section{NUMERICAL ILLUSTRATIONS AND SENSITIVITY ANALYSIS}

We set the holding cost $\mathrm{h}$ to be $\$ 5$ and $\$ 20$. We should mention that the $\mathrm{D}$ policy is applied to manage the queuing system due to expensive cost (R) which denotes the sum of the cost for turning the server on and the cost for turning the server off. The cost $\mathrm{R}$ is relative to the holding cost $h$. We set the ratio $R / h$ to be 160, 320 and 640, in order to cover three levels of cost relationship (cases 1-3). Numerical results are provided by considering the cost parameters shown in Table 1 .

It is to be noted that $0<p=\lambda / \mu<1$ is sufficient for steady-state condition. In our numerical investigations, the traffic intensity $\rho \in(0.1,0.9)$ is considered. In Table 2, row 2 list the parameter settings for various values of $\lambda$. We fix $\alpha=0.1$ and $\beta=1.0$, choose $\mu=1.0$ and vary $\rho$ from 0.1 to 0.9 (low to high). Solving $\rho=$ $\lambda / \mu$ for $\lambda$, we obtain $\lambda=0.1(0.05) 0.9$. Row 3 list the parameter settings for various values of $\mu$. We fix $\alpha=$ 0.1 and $\beta=1.0$, choose $\lambda=0.45$ and vary $\rho$ from 0.1 to 0.9. Again, solving $\rho=\lambda / \mu$ for $\mu$, we obtain $\mu=$ $0.5(0.25) 4.5$. Row 4 list the parameter settings for various values of $\alpha$. We choose $\lambda=0.45, \mu=1.0$ and $\beta=1.0$ and consider $\alpha=0.1(0.05) 0.9$. Row 5 list the parameter settings for various values of $\beta$. We select $\lambda$ $=0.45, \mu=1.0$ and $\alpha=1.0$ and consider $\beta=$ 1.0(0.5)9.0.

\begin{tabular}{lcll}
\multicolumn{4}{l}{ Table 1: The costs for each case } \\
\hline Case & $\mathrm{h}$ & $\mathrm{R}$ & $\mathrm{R} / \mathrm{h}$ \\
1 & 5 & 1600 & 320 \\
2 & 5 & 3200 & 640 \\
3 & 20 & 3200 & 160 \\
\hline
\end{tabular}

Table 2: Parameters settings for various system parameters

\begin{tabular}{lllll}
\hline$\lambda$ & $\mu$ & $\alpha$ & $\beta$ & Parameters settings \\
\hline- & 1.0 & 0.1 & 1.0 & $\lambda=0.1(0.05) 0.9$ \\
0.45 & - & 0.1 & 1.0 & $\mu=0.5(0.25) 4.5$ \\
0.45 & 1.0 & - & 1.0 & $\alpha=0.1(0.05) 0.9$ \\
0.45 & 1.0 & 1.0 & - & $\beta=1.0(0.5) 9.0$ \\
\hline
\end{tabular}


Am. J. Applied Sci., 5 (5): 565-573, 2008

\begin{tabular}{|c|c|c|c|c|c|c|c|c|c|c|c|c|c|c|c|c|c|c|}
\hline$\lambda$ & & 0.1 & 0.15 & 0.2 & 0.25 & 0.3 & 0.35 & 0.4 & 0.45 & 0.5 & 0.55 & 0.6 & 0.65 & 0.7 & 0.75 & 0.8 & 0.85 & 0.9 \\
\hline \multirow[t]{2}{*}{ Case 1} & $\mathrm{D}^{*}$ & 6.80 & 26 & & 10.16 & 10.76 & 11.17 & 11.42 & 11.51 & 11.44 & 11.23 & 10.84 & 10.28 & 9.51 & 8.48 & 7.10 & 5.14 & 1.56 \\
\hline & $\mathrm{F}(\mathrm{D})$ & & & & & & & & & & & & & & & & & 597.29 \\
\hline \multirow[t]{2}{*}{ Case 2} & $\mathrm{D}^{*}$ & & & & & & & & & & & & & & & & 7.70 & 2.54 \\
\hline & $\mathrm{F}(\mathrm{I}$ & & & & & & 84. & & & 90. & 90.7 & 90. & & 89.4 & & 10 & 124.14 & 602.18 \\
\hline \multirow[t]{2}{*}{ Case 3} & $\mathrm{D}^{*}$ & & 5. & & & & & & 7.8 & 7.78 & & & 6.96 & 6.42 & 5.70 & 4.73 & 3.36 & 0.90 \\
\hline & $\mathrm{F}(\mathrm{D})$ & 93.23 & 115.51 & 132.74 & 146.49 & 157.59 & 166.58 & 173.86 & 179.76 & 184.65 & 188.95 & 193.33 & 198.94 & 208.09 & 226.19 & 269.19 & 409.72 & 2376.1 \\
\hline
\end{tabular}

Table 4: The optimal value $\mathrm{D}^{*}$ and its minimum expected $\operatorname{cost} \mathrm{F}\left(\mathrm{D}^{*}\right)$ for $\lambda=0.45, \alpha=0.1$ and $\beta=1.0$ (the $D$ policy $\mathrm{M} / \mathrm{M} / 1$ queueing system with server breakdowns)

\begin{tabular}{|c|c|c|c|c|c|c|c|c|c|c|c|c|c|c|c|c|c|c|}
\hline \multirow{3}{*}{$\frac{\mu}{\text { Case } 1}$} & & 0.5 & 0.75 & 1 & 1.25 & 1.5 & 1.75 & 2 & 2.25 & 2.5 & 2.75 & 3 & 3.25 & 3.5 & 3.75 & 4 & 4.25 & 4.5 \\
\hline & D* & 1.08 & 10.52 & 11.51 & 11.43 & 11.09 & 10.69 & 10.29 & 9.91 & 9.55 & 9.23 & 8.93 & 8.66 & 8.41 & 8.18 & 7.96 & 7.76 & 7.57 \\
\hline & $F(D)$ & 1139.40 & 67.71 & 63.37 & 60.34 & 57.49 & 54.86 & 52.49 & 50.35 & 48.43 & 46.69 & 45.12 & 43.69 & 42.38 & 41.17 & 40.06 & 39.04 & 38.08 \\
\hline \multirow[t]{2}{*}{ Case 2} & $\mathrm{D}^{*}$ & 1.92 & 15.46 & 16.73 & 16.55 & 16.01 & 15.40 & 14.81 & 14.25 & 13.73 & 13.26 & 12.82 & 12.43 & 12.06 & 11.72 & 11.41 & 11.12 & 10.86 \\
\hline & $F(D)$ & 1143.60 & 92.40 & 89.49 & 85.92 & 82.09 & 78.44 & 75.08 & 72.04 & 69.30 & 66.82 & 64.57 & 62.51 & 60.64 & 58.91 & 57.32 & 55.85 & 54.48 \\
\hline \multirow[t]{2}{*}{ Case 3} & $\mathrm{D}^{*}$ & 0.58 & 7.05 & 7.82 & 7.82 & 7.62 & 7.36 & 7.09 & 6.84 & 6.60 & 6.38 & 6.18 & 6.00 & 5.83 & 5.67 & 5.52 & 5.38 & 5.25 \\
\hline & $F(D)$ & 4547.50 & 201.41 & 179.76 & 169.13 & 160.43 & 152.82 & 146.07 & 140.07 & 134.69 & 129.85 & 125.47 & 121.49 & 117.85 & 114.50 & 111.42 & 108.56 & 105.91 \\
\hline
\end{tabular}

Table 5: The optimal value $\mathrm{D}^{*}$ and its minimum expected cost $\mathrm{F}\left(\mathrm{D}^{*}\right)$ for $\lambda=0.45, \mu=1.0$ and $\beta=1.0$ (the $D$ policy $\mathrm{M} / \mathrm{M} / 1$ queueing system with server breakdowns)

\begin{tabular}{|c|c|c|c|c|c|c|c|c|c|c|c|c|c|c|c|c|c|c|}
\hline \multirow{2}{*}{$\frac{\alpha}{\text { Case } 1}$} & & 0.1 & 0.15 & 0.2 & 0.25 & 0.3 & 0.35 & 0.4 & 0.45 & 0.5 & 0.55 & 0.6 & 0.65 & 0.7 & 0.75 & 0.8 & 0.85 & 0.9 \\
\hline & $\mathrm{D}^{*}$ & 11.51 & 11.41 & 11.30 & 11.16 & 11.01 & 10.82 & 10.61 & 10.38 & 10.12 & 9.83 & 9.51 & 9.16 & 8.77 & 8.34 & 7.87 & 7.35 & 6.77 \\
\hline & $F(D)$ & 63.37 & 63.94 & 64.52 & 65.14 & 65.82 & 66.56 & 67.42 & 68.43 & 69.64 & 71.11 & 72.94 & 75.25 & 78.21 & 82.06 & 87.18 & 94.12 & 103.83 \\
\hline \multirow[t]{2}{*}{ Case 2} & $\mathrm{D}^{*}$ & 16.73 & 16.63 & 16.51 & 16.34 & 16.15 & 15.92 & 15.65 & 15.34 & 15.00 & 14.61 & 14.18 & 13.70 & 13.17 & 12.58 & 11.92 & 11.20 & 10.39 \\
\hline & $F(D)$ & 89.49 & 90.04 & 90.55 & 91.04 & 91.53 & 92.04 & 92.59 & 93.24 & 94.03 & 95.01 & 96.28 & 97.96 & 100.20 & 103.25 & 107.46 & 113.39 & 121.94 \\
\hline \multirow[t]{2}{*}{ Case 3} & $\mathrm{D}^{*}$ & 7.82 & 7.73 & 7.63 & 7.52 & 7.38 & 7.24 & 7.07 & 6.89 & 6.69 & 6.47 & 6.23 & 5.97 & 5.69 & 5.38 & 5.04 & 4.66 & 4.25 \\
\hline & $\mathrm{F}(\mathrm{D})$ & 179.76 & 182.13 & 184.72 & 187.59 & 190.83 & 194.54 & 198.85 & 203.93 & 209.98 & 217.30 & 226.24 & 237.32 & 251.23 & 268.99 & 292.08 & 322.83 & 364.99 \\
\hline
\end{tabular}

Table 6: The optimal value $\mathrm{D}^{*}$ and its minimum expected cost $\mathrm{F}(\mathrm{D} *)$ for $\lambda=0.45, \mu=1.0$ and $\alpha=1.0$ (the $\mathrm{D}$ policy $\mathrm{M} / \mathrm{M} / 1$ queueing system with server breakdowns)

\begin{tabular}{|c|c|c|c|c|c|c|c|c|c|c|c|c|c|c|c|c|c|c|}
\hline \multirow{3}{*}{$\frac{\beta}{\text { Case } 1}$} & & 1 & 1.5 & 2 & 2.5 & 3 & 3.5 & 4 & 4.5 & 5 & 5.5 & 6 & 6.5 & 7 & 7.5 & 8 & 8.5 & 9 \\
\hline & & & 9.17 & & 10.79 & & 11.21 & & 11.39 & & 11.47 & 11.50 & 11.52 & & 11.55 & 11.56 & 11.57 & \\
\hline & & & & & & & & & & & & & & & & & & \\
\hline \multirow[t]{2}{*}{ Case 2} & & & & & & & & & & & & & & & & & & \\
\hline & & & & & & & & & & & & & & & & & & 89.62 \\
\hline \multirow[t]{2}{*}{ Case 3} & & & 6.02 & & 7.25 & & & 7.67 & & & & & 7.84 & & 7.87 & 7.88 & 7.89 & 7.89 \\
\hline & (D) & 515.84 & 36.38 & 206.49 & 96.52 & 91.64 & 188.72 & 86.77 & 185.36 & 84.28 & 183.43 & 182.74 & 182.16 & 181.67 & 81.25 & 180.89 & 180.57 & 80.29 \\
\hline
\end{tabular}

The purpose of this section is to present specific numerical illustrations and sensitivity analysis for three different service time distributions such as exponential (M), 3-stage Erlang $\left(\mathrm{E}_{3}\right)$ and deterministic, respectively. This section consists of the following three subsections:

- Numerical illustrations and sensitivity analysis for the $\mathrm{D}$ policy $\mathrm{M} / \mathrm{M} / 1$ queueing system with server breakdowns;

- Numerical illustrations and sensitivity analysis for the $\mathrm{D}$ policy $\mathrm{M} / \mathrm{E}_{3} / 1$ queueing system with server breakdowns;

- Numerical illustrations and sensitivity analysis for the $\mathrm{D}$ policy $\mathrm{M} / \mathrm{D} / 1$ queueing system with server breakdowns.

The M/M/1 queueing system: First, we perform some numerical illustrations and sensitivity analysis for the D policy M/M/1 queueing system with server breakdowns. The optimum value $\mathrm{D}^{*}$ is shown on changes in specific values of $\lambda, \mu, \alpha$ and $\beta$. Using the parameters settings listed in Table 1 and 2 , we obtain the numerical results for the optimal value $\mathrm{D}^{*}$ and the corresponding minimum expected cost $\mathrm{F}(\mathrm{D})$ shown in Table 3-6.
The optimal value $\mathrm{D}^{*}$ and its minimum expected cost $\mathrm{F}\left(\mathrm{D}^{*}\right)$ are presented in Table 3 for parameter $\mu=$ $1.0, \alpha=0.1, \beta=1.0$ and $\lambda=0.1(0.05) 0.9$, as the case shown in Table 2 (row 2). We observe from Table 3 that (i) for $\rho_{\mathrm{H}}<1 / 2, D^{*}$ increases as $\lambda$ increases for any case and for $\rho_{\mathrm{H}}<1 / 2, \mathrm{D}^{*}$ decreases as $\lambda$ increases for any case, (ii) $\mathrm{F}\left(\mathrm{D}^{*}\right)$ increases as $\lambda$ increases (see cases $1,3)$, (iii) for fixed values of $h, D^{*}$ and $F\left(D^{*}\right)$ both increase as $\mathrm{R}$ increases (see cases 1,2) and (iv) for fixed values of $\mathrm{R}, \mathrm{D}^{*}$ decreases but $\mathrm{F}\left(\mathrm{D}^{*}\right)$ increases as $\mathrm{h}$ increases (cases 2, 3).

The optimal value $\mathrm{D}^{*}$ and its minimum expected cost $\mathrm{F}\left(\mathrm{D}^{*}\right)$ are displayed in Table 4 , for parameter $\lambda=$ $0.45, \alpha=0.1, \beta=1.0$ and $\mu=0.5(0.25) 4.5$, as the case shown in Table 2 (see row 3 ). One sees from Table 4 that (i) for $\mu<1.0, D^{*}$ increases as $\mu$ increases for any case and for $\mu>1.0, D^{*}$ decreases as $\mu$ increases for any case, (ii) $\mathrm{F}\left(\mathrm{D}^{*}\right)$ decreases as $\mu$ increases for any case, (iii) for fixed values of $h, D^{*}$ and $F\left(D^{*}\right)$ both increase as $R$ increases (cases 1,2) and (iv) for fixed values of $\mathrm{R}, \mathrm{D}^{*}$ decreases but $\mathrm{F}\left(\mathrm{D}^{*}\right)$ increases as $\mathrm{h}$ increases (cases 2, 3).

The optimal value $\mathrm{D}^{*}$ and its minimum expected cost $\mathrm{F}\left(\mathrm{D}^{*}\right)$ are presented in Table 5 , for parameter $\lambda=$ $0.45, \mu=1.0, \beta=1.0$ and $\alpha=0.1(0.05) 0.9$, as the case 
Am. J. Applied Sci., 5 (5): 565-573, 2008

Table 7: The optimal value $\mathrm{D}^{*}$ and its minimum expected $\operatorname{cost} \mathrm{F}\left(\mathrm{D}^{*}\right)$ for $\mu=1.0, \alpha=0.1$ and $\beta=1.0$ (the $\mathrm{D}$ policy $\mathrm{M} / \mathrm{E}_{3} / 1$ queueing system with server breakdowns)

\begin{tabular}{|c|c|c|c|c|c|c|c|c|c|c|c|c|c|c|c|c|c|c|}
\hline \multirow{2}{*}{$\frac{\lambda}{\text { Case } 1}$} & & 0.1 & 0.15 & 0.2 & 0.25 & 0.3 & 0.35 & 0.4 & 0.45 & 0.5 & 0.55 & 0.6 & 0.65 & 0.7 & 0.75 & 0.8 & 0.85 & 0.9 \\
\hline & & & & 9.70 & 10.5 & 1111 & 153 & 11.78 & 1.87 & 1 & & 21 & 0.64 & 9.87 & 8.84 & 7.45 & 5.47 & 1.8 \\
\hline & & & & & & & & & & & & & & & & & 84.47 & 01.98 \\
\hline \multirow[t]{2}{*}{ ase 2} & D & & & & & & & & & & & & & & & & & 2.82 \\
\hline & & & & & & & & & & & & & & & & & 97.34 & 07.09 \\
\hline \multirow[t]{2}{*}{ ase 3} & D & & & & & & & & & & & & & & & & 3.66 & 1.09 \\
\hline & $F(D)$ & 98.70 & 120.62 & 137.31 & 150.36 & 160.62 & 168.58 & 174.61 & 178.98 & 181.94 & 83.77 & 184.87 & 85.93 & 88.34 & 95.47 & 217.47 & 301.58 & 1593.80 \\
\hline
\end{tabular}

Table 8. The optimal value $\mathrm{D}^{*}$ and its minimum expected cost $\mathrm{F}\left(\mathrm{D}^{*}\right)$ for $\lambda=0.45, \alpha=0.1$ and $\beta=1.0$ (the $\mathrm{D}$ policy $\mathrm{M} / \mathrm{E}_{3} / 1$ queueing system with server breakdowns)

\begin{tabular}{|c|c|c|c|c|c|c|c|c|c|c|c|c|c|c|c|c|c|c|}
\hline \multirow{3}{*}{$\frac{\mu}{\text { Case } 1}$} & & 0.5 & 0.75 & 1 & 1.25 & 1.5 & 1.75 & 2 & 2.25 & 2.5 & 2.75 & 3 & 3.25 & 3.5 & 3.75 & 4 & 4.25 & 4.5 \\
\hline & D* & 1.28 & 10.97 & 11.87 & 11.73 & 11.35 & 10.92 & 10.49 & 10.10 & 9.73 & 9.39 & 9.09 & 8.80 & 8.54 & 8.31 & 8.09 & 7.88 & 7.69 \\
\hline & $\mathrm{F}(\mathrm{D})$ & 762.40 & 64.95 & 63.24 & 60.79 & 58.11 & 55.54 & 53.17 & 51.02 & 49.08 & 47.32 & 45.73 & 44.27 & 42.94 & 41.72 & 40.60 & 39.56 & 38.59 \\
\hline \multirow[t]{2}{*}{ Case 2} & $\mathrm{D}^{*}$ & 2.24 & 15.93 & 17.10 & 16.86 & 16.28 & 15.64 & 15.01 & 14.44 & 13.90 & 13.42 & 12.97 & 12.57 & 12.20 & 11.85 & 11.54 & 11.24 & 10.97 \\
\hline & $\mathrm{F}(\mathrm{D})$ & 767.21 & 89.73 & 89.41 & 86.40 & 82.74 & 79.13 & 75.78 & 72.72 & 69.96 & 67.45 & 65.17 & 63.10 & 61.20 & 59.46 & 57.85 & 56.37 & 54.98 \\
\hline \multirow[t]{2}{*}{ Case 3} & $\mathrm{D}^{*}$ & 0.64 & 7.48 & 8.17 & 8.11 & 7.87 & 7.58 & 7.30 & 7.03 & 6.78 & 6.55 & 6.33 & 6.14 & 5.96 & 5.80 & 5.64 & 5.50 & 5.37 \\
\hline & $\mathrm{F}(\mathrm{D})$ & 3036.90 & 189.83 & 178.98 & 170.78 & 162.83 & 155.45 & 148.75 & 142.71 & 137.27 & 132.36 & 127.90 & 123.84 & 120.13 & 116.72 & 113.58 & 110.67 & 107.96 \\
\hline
\end{tabular}

Table 9: The optimal value $\mathrm{D}^{*}$ and its minimum expected $\operatorname{cost} \mathrm{F}\left(\mathrm{D}^{*}\right)$ for $\lambda=0.45, \mu=1.0$ and $\beta=1.0$ (the $D$ policy $\mathrm{M} / \mathrm{E}_{3} / 1$ queueing system with server breakdowns)

\begin{tabular}{|c|c|c|c|c|c|c|c|c|c|c|c|c|c|c|c|c|c|c|}
\hline \multirow{3}{*}{$\frac{\alpha}{\text { Case 1 }}$} & & 0.1 & 0.15 & 0.2 & 0.25 & 0.3 & 0.35 & 0.4 & 0.45 & 0.5 & 0.55 & 0.6 & 0.65 & 0.7 & 0.75 & 0.8 & 0.85 & 0.9 \\
\hline & $\mathrm{D}^{*}$ & 11.87 & 11.80 & 11.72 & 11.60 & 11.47 & 11.31 & 11.12 & 10.90 & 10.66 & 10.39 & 10.08 & 9.75 & 9.37 & 8.95 & 8.49 & 7.98 & 7.40 \\
\hline & $F(D)$ & 63.24 & 63.60 & 63.93 & 64.23 & 64.53 & 64.83 & 65.16 & 65.54 & 66.00 & 66.58 & 67.35 & 68.37 & 69.76 & 71.68 & 74.35 & 78.15 & 83.68 \\
\hline \multirow[t]{2}{*}{ Case 2} & $\mathrm{D}^{*}$ & 17.10 & 17.04 & 16.93 & 16.80 & 16.62 & 16.42 & 16.17 & 15.88 & 15.56 & 15.19 & 14.78 & 14.31 & 13.80 & 13.22 & 12.58 & 11.87 & 11.07 \\
\hline & $F(D)$ & 89.41 & 89.76 & 90.01 & 90.20 & 90.31 & 90.38 & 90.41 & 90.44 & 90.49 & 90.59 & 90.81 & 91.21 & 91.90 & 93.03 & 94.81 & 97.61 & 102.01 \\
\hline \multirow[t]{2}{*}{ Case 3} & $\mathrm{D}^{*}$ & 8.17 & 8.11 & 8.03 & 7.94 & 7.83 & 7.70 & 7.55 & 7.39 & 7.20 & 7.00 & 6.77 & 6.52 & 6.25 & 5.95 & 5.61 & 5.24 & 4.83 \\
\hline & $F(D)$ & 178.98 & 180.48 & 182.01 & 183.59 & 185.29 & 187.17 & 189.32 & 191.84 & 194.87 & 198.57 & 203.20 & 209.07 & 216.64 & 226.55 & 239.78 & 257.84 & 283.18 \\
\hline
\end{tabular}

Table 10: The optimal value $\mathrm{D}^{*}$ and its minimum expected cost $\mathrm{F}\left(\mathrm{D}^{*}\right)$ for for $\lambda=0.45, \mu=1.0$ and $\alpha=1.0$ (the $\mathrm{D}$ policy $\mathrm{M} / \mathrm{E}_{3} / 1$ queueing system with server breakdowns)

\begin{tabular}{|c|c|c|c|c|c|c|c|c|c|c|c|c|c|c|c|c|c|c|}
\hline \multirow{3}{*}{$\frac{\beta}{\text { Case } 1}$} & & 1 & 1.5 & 2 & 2.5 & 3 & 3.5 & 4 & 4.5 & 5 & 5.5 & 6 & 6.5 & 7 & 7.5 & 8 & 8.5 & 9 \\
\hline & & 6.03 & .71 & 10.77 & 1.23 & 11.47 & 11.61 & 11.70 & 11.76 & 11.80 & 11. & 11.86 & 11.87 & 11.89 & 11.90 & 11.90 & 1.91 & 11.92 \\
\hline & & & & & & & & & & & & & & & & & & 3.32 \\
\hline \multirow[t]{2}{*}{ Case 2} & & & & & & & & & & & & & & & & & & \\
\hline & & & & & & & & & & & & & & & & & & 89.50 \\
\hline \multirow[t]{2}{*}{ ase 3} & D & 3.8 & 6. & & 7. & 7.8 & & & 8. & & & 8.16 & & & & & 8.21 & 8.22 \\
\hline & $F(D)$ & 376.93 & 07.83 & 192.47 & 187.71 & 185.40 & 183.99 & 183.01 & 182.27 & 181.68 & 181.21 & 180.81 & 180.47 & 180.17 & 179.92 & 179.69 & 179.49 & 79.3 \\
\hline
\end{tabular}

Table 11: The optimal value $D^{*}$ and its minimum expected cost $\mathrm{F}\left(\mathrm{D}^{*}\right)$ for $\mu=1.0, \alpha=0.1$ and $\beta=1.0$ (the $\mathrm{D}$ policy $\mathrm{M} / \mathrm{D} / 1$ queueing system with server breakdowns)

\begin{tabular}{|c|c|c|c|c|c|c|c|c|c|c|c|c|c|c|c|c|c|c|}
\hline$\lambda$ & & 0.1 & 0.15 & 0.2 & 0.25 & 0.3 & 0.35 & 0.4 & 0.45 & 0.5 & 0.55 & 0.6 & 0.65 & 0.7 & 0.75 & 0.8 & 0.85 & 0.9 \\
\hline \multirow{2}{*}{ Case 1} & D* & 7.33 & 8.80 & 9.89 & 10.71 & 11.31 & 11.72 & 11.97 & 12.06 & 12.00 & 11.78 & 11.39 & 10.83 & 10.06 & 9.02 & 7.63 & 5.65 & 1.95 \\
\hline & $\mathrm{F}(\mathrm{D})$ & 37.01 & 44.59 & 50.29 & 54.66 & 57.99 & 60.46 & 62.17 & 63.21 & 63.61 & 63.44 & 62.75 & 61.62 & 60.25 & 59.15 & 60.00 & 71.08 & 304.48 \\
\hline \multirow[t]{2}{*}{ Case 2} & $\mathrm{D}^{*}$ & 10.60 & 12.69 & 14.23 & 15.38 & 16.23 & 16.82 & 17.17 & 17.30 & 17.21 & 16.90 & 16.36 & 15.56 & 14.46 & 13.00 & 11.04 & 8.23 & 2.98 \\
\hline & $\mathrm{F}(\mathrm{D})$ & 53.39 & 64.03 & 71.99 & 78.05 & 82.62 & 85.95 & 88.18 & 89.40 & 89.67 & 89.05 & 87.56 & 85.26 & 82.29 & 79.05 & 77.01 & 83.98 & 309.65 \\
\hline \multirow[t]{2}{*}{ Case 3} & $\mathrm{D}^{*}$ & 5.01 & 6.05 & 6.82 & 7.40 & 7.82 & 8.12 & 8.29 & 8.36 & 8.31 & 8.16 & 7.89 & 7.49 & 6.94 & 6.21 & 5.23 & 3.83 & 1.22 \\
\hline & $\mathrm{F}(\mathrm{D})$ & 101.72 & 123.42 & 139.81 & 152.51 & 162.33 & 169.77 & 175.17 & 178.77 & 180.77 & 181.36 & 180.83 & 179.62 & 178.68 & 180.35 & 191.89 & 247.87 & 1203.30 \\
\hline
\end{tabular}

shown in Table 2 (row 4). From Table 5 we find that (i) $\mathrm{D}^{*}$ decreases as $\alpha$ increases for any case, (ii) $\mathrm{F}\left(\mathrm{D}^{*}\right)$ increases as $\alpha$ increases for any case, (iii) for fixed values of $h, D^{*}$ and $F\left(D^{*}\right)$ both increase as $R$ increases (cases 1,2 ) and (iv) for fixed values of $\mathrm{R}, \mathrm{D}^{*}$ decreases but $\mathrm{F}\left(\mathrm{D}^{*}\right)$ increases as $\mathrm{h}$ increases (cases 2,3 ).

The optimal value $\mathrm{D}^{*}$ and its minimum expected cost $F\left(D^{*}\right)$ are displayed in Table 6 , for parameter $\lambda=$ $0.45, \mu=1.0, \alpha=1.0$ and $\beta=1.0(0.5) 9.0$, as the case shown in Table 2 (row 5). From Table 6 we observe that (i) $D^{*}$ increases as $\beta$ increases for any case, (ii) $\mathrm{F}\left(\mathrm{D}^{*}\right)$ decreases as $\beta$ increases for any case, (iii) for fixed values of $\mathrm{h}, \mathrm{D}^{*}$ and $\mathrm{F}\left(\mathrm{D}^{*}\right)$ both increase as $\mathrm{R}$ increases (cases 1,2) and (iv) for fixed values of R, D* decreases but $\mathrm{F}\left(\mathrm{D}^{*}\right)$ increases as $\mathrm{h}$ increases (cases 2, 3).
The $\mathbf{M} / \mathbf{E}_{\mathbf{3}} / \mathbf{1}$ queueing system: We perform the numerical illustrations and sensitivity analysis on the optimum value $\mathrm{D}^{*}$ based on changes in specific values of $\lambda, \mu, \alpha$ and $\beta$, for the $D$ policy $M / E_{3} / 1$ queueing system with server breakdowns. Using the parameters settings listed in Table 1 and 2, we obtain the numerical results for the optimal value $\mathrm{D}^{*}$ and the corresponding minimum expected cost $\mathrm{F}(\mathrm{D})$ shown in Table 7-10. The interpretations of the results in Table 7-10 are the same as those in Table 3-6.

The M/D/1 queueing system: We now present the numerical illustrations and sensitivity analysis for the $\mathrm{M} / \mathrm{D} / 1$ queueing system. The optimum value $\mathrm{D}^{*}$ is shown on changes in specific values of $\lambda, \mu, \alpha$ and $\beta$. Using the parameters settings listed in Table 1 and 2 , 
Am. J. Applied Sci., 5 (5): 565-573, 2008

Table 12: The optimal value $D^{*}$ and its minimum expected cost $F\left(D^{*}\right)$ for $\lambda=0.45, \alpha=0.1$ and $\beta=1.0$ (the $D$ policy M/D/1 queueing system with server breakdowns)

\begin{tabular}{|c|c|c|c|c|c|c|c|c|c|c|c|c|c|c|c|c|c|c|}
\hline$\mu$ & & 0.5 & 0.75 & 1 & 1.25 & 1.5 & 1.75 & 2 & 2.25 & 2.5 & 2.75 & 3 & 3.25 & 3.5 & 3.75 & 4 & 4.25 & 4.5 \\
\hline \multirow[t]{2}{*}{ Case 1} & $\mathrm{D}^{*}$ & 1.46 & 11.21 & 12.06 & 11.89 & 11.49 & 11.04 & 10.60 & 10.19 & 9.82 & 9.47 & 9.16 & 8.88 & 8.61 & 8.37 & 8.15 & 7.94 & 7.75 \\
\hline & $\mathrm{F}(\mathrm{D})$ & 574.32 & 63.63 & 63.21 & 61.04 & 58.44 & 55.89 & 53.52 & 51.36 & 49.41 & 47.64 & 46.03 & 44.57 & 43.23 & 42.00 & 40.86 & 39.81 & 38.84 \\
\hline \multirow[t]{2}{*}{ Case 2} & $D^{*}$ & 2.48 & 16.18 & 17.30 & 17.01 & 16.41 & 15.75 & 15.12 & 14.53 & 13.99 & 13.50 & 13.05 & 12.64 & 12.26 & 11.92 & 11.60 & 11.30 & 11.03 \\
\hline & $\mathrm{F}(\mathrm{D})$ & 579.40 & 88.44 & 89.40 & 86.66 & 83.08 & 79.48 & 76.13 & 73.06 & 70.29 & 67.77 & 65.48 & 63.39 & 61.49 & 59.73 & 58.12 & 56.62 & 55.23 \\
\hline \multirow[t]{2}{*}{ Case 3} & D* & 0.76 & 7.71 & 8.36 & 8.27 & 8.00 & 7.70 & 7.40 & 7.12 & 6.86 & 6.63 & 6.41 & 6.21 & 6.03 & 5.86 & 5.71 & 5.56 & 5.43 \\
\hline & $\mathrm{F}(\mathrm{D})$ & 2283.20 & 184.39 & 178.77 & 171.71 & 164.10 & 156.81 & 150.12 & 144.06 & 138.58 & 133.62 & 129.12 & 125.02 & 121.27 & 117.82 & 114.65 & 111.71 & 108.97 \\
\hline
\end{tabular}

Table 13: The optimal value $\mathrm{D}^{*}$ and its minimum expected cost $\mathrm{F}\left(\mathrm{D}^{*}\right)$ for $\lambda=0.45, \mu=1.0$ and $\beta=1.0$ (the $\mathrm{D}$ policy $\mathrm{M} / \mathrm{D} / 1$ queueing system with server breakdowns)

\begin{tabular}{|c|c|c|c|c|c|c|c|c|c|c|c|c|c|c|c|c|c|c|}
\hline$\alpha$ & 0.1 & 0.15 & 0.2 & 0.25 & 0.3 & 0.35 & 0.4 & 0.45 & 0.5 & 0.55 & 0.6 & 0.65 & 0.7 & 0.75 & 0.8 & 0.85 & 0.9 & \\
\hline \multirow[t]{2}{*}{ Case 1} & D* & 12.06 & 12.01 & 11.93 & 11.83 & 11.71 & 11.56 & 11.38 & 11.18 & 10.95 & 10.68 & 10.39 & 10.06 & 9.69 & 9.28 & 8.83 & 8.32 & 7.75 \\
\hline & $\mathrm{F}(\mathrm{D})$ & 63.21 & 63.47 & 63.67 & 63.82 & 63.93 & 64.02 & 64.08 & 64.15 & 64.24 & 64.39 & 64.63 & 65.02 & 65.63 & 66.59 & 68.05 & 70.29 & 73.75 \\
\hline \multirow[t]{2}{*}{ Case 2} & $\mathrm{D}^{*}$ & 17.30 & 17.24 & 17.15 & 17.03 & 16.87 & 16.67 & 16.44 & 16.16 & 15.85 & 15.49 & 15.09 & 14.63 & 14.13 & 13.56 & 12.93 & 12.22 & 11.43 \\
\hline & $\mathrm{F}(\mathrm{D})$ & 89.40 & 89.64 & 89.77 & 89.80 & 89.74 & 89.59 & 89.36 & 89.08 & 88.77 & 88.44 & 88.13 & 87.90 & 87.82 & 87.99 & 88.57 & 89.82 & 92.15 \\
\hline \multirow[t]{2}{*}{ Case 3} & $\mathrm{D}^{*}$ & 8.36 & 8.31 & 8.24 & 8.16 & 8.06 & 7.94 & 7.81 & 7.65 & 7.48 & 7.28 & 7.07 & 6.82 & 6.56 & 6.26 & 5.93 & 5.56 & 5.15 \\
\hline & $F(D)$ & 178.77 & 179.86 & 180.87 & 181.83 & 182.78 & 183.77 & 184.87 & 186.13 & 187.67 & 189.61 & 192.11 & 195.42 & 199.86 & 205.91 & 214.27 & 226.04 & 243.05 \\
\hline
\end{tabular}

Table 14: The optimal value $\mathrm{D}^{*}$ and its minimum expected cost $\mathrm{F}\left(\mathrm{D}^{*}\right)$ for $\lambda=0.45, \mu=1.0$ and $\alpha=1.0$ (the $\mathrm{D}$ policy $\mathrm{M} / \mathrm{D} / 1$ queueing system with server breakdowns)

\begin{tabular}{|c|c|c|c|c|c|c|c|c|c|c|c|c|c|c|c|c|c|c|}
\hline$\beta$ & & 1 & 1.5 & 2 & 2.5 & 3 & 3.5 & 4 & 4.5 & 5 & 5.5 & 6 & 6.5 & 7 & 7.5 & 8 & 8.5 & 9 \\
\hline \multirow[t]{2}{*}{ Case 1} & D* & 6.38 & 10.01 & 11.03 & 11.47 & 11.69 & 11.82 & 11.91 & 11.96 & 12.00 & 12.02 & 12.04 & 12.06 & 12.07 & 12.08 & 12.08 & 12.09 & 12.09 \\
\hline & $\mathrm{F}(\mathrm{D})$ & 88.15 & 64.52 & 63.79 & 63.78 & 63.78 & 63.75 & 63.71 & 63.66 & 63.61 & 63.55 & 63.50 & 63.46 & 63.41 & 63.37 & 63.34 & 63.30 & 63.27 \\
\hline \multirow[t]{2}{*}{ Case 2} & $D^{*}$ & 9.51 & 14.54 & 15.93 & 16.52 & 16.82 & 17.00 & 17.10 & 17.17 & 17.22 & 17.25 & 17.27 & 17.29 & 17.30 & 17.31 & 17.32 & 17.33 & 17.33 \\
\hline & $\mathrm{F}(\mathrm{D})$ & 103.81 & 87.19 & 88.31 & 89.06 & 89.43 & 89.61 & 89.69 & 89.72 & 89.71 & 89.69 & 89.66 & 89.63 & 89.59 & 89.56 & 89.52 & 89.49 & 89.46 \\
\hline \multirow[t]{2}{*}{ Case 3} & $\mathrm{D}^{*}$ & 4.17 & 6.80 & 7.56 & 7.89 & 8.07 & 8.17 & 8.23 & 8.28 & 8.31 & 8.33 & 8.34 & 8.36 & 8.37 & 8.37 & 8.38 & 8.39 & 8.39 \\
\hline & $\mathrm{F}(\mathrm{D})$ & 308.45 & 194.07 & 185.85 & 183.63 & 182.57 & 181.89 & 181.37 & 180.96 & 180.61 & 180.31 & 180.06 & 179.83 & 179.63 & 179.45 & 179.29 & 179.14 & 179.01 \\
\hline
\end{tabular}

we obtain the numerical results for the optimal value $\mathrm{D}^{*}$ and the corresponding minimum expected cost F(D) shown in Table 11-14. The interpretations of the results in Table 11-14 are the same as those in Table 3-6.

\section{CONCLUSION}

In this study we have developed analytic steadystate results for the M/G/1 queueing system with server breakdowns operating under the D-policy. More especially, we approximated the first two moments of $R_{D}$ as well as the renewal quantities $M_{H}(D)$ and $\int_{0}^{D} M_{H}(y) d y$. It is important to mention that the probability that the server is busy is $\rho$. We derive the optimum value of the control parameter $\mathrm{D}$ so as to minimize the total expected cost function per customer per unit time. Numerical illustrations and sensitivity analysis are provided for three different service time distributions, exponential, 3-stage Erlang and deterministic.

\section{REFERENCES}

1. Balachandran, K.R., 1973. Control policies for a single server system. Manage. Sci., 19: 1013-1018.
2. Balachandran, K.R. and H. Tijms, 1975. On the D-policy for the $M / G / 1$ queue. Manage. Sci., 21: 1073-1076.

3. Gakis, K.G., H.K. Rhee and B.D. Sivazlian, 1995. Distributions and first moments of the busy and idle periods in controllable $\mathrm{M} / \mathrm{G} / 1$ queueing models with simple and dyadic policies. Stochastic Anal. Applic., 13: 47-81.

4. Li, J. and S.C. Niu, 1992. The waiting-time distribution for the GI/G/1 queue under the Dpolicy. Probab. Eng. Inform. Sci., 6: 287-308.

5. Sivazlian, B.D., 1979. Approximate optimal solution for a D-policy in an M/G/1 queueing system. AIIE Trans., 11: 341-343.

6. Tijms, H.C., 1986. Stochastic Modeling and Analysis: A Computational Approach. John Wiley and Sons, New York.

7. Wang, K.H. and J.C. Ke, 2002. Control policies of an M/G/1 queueing system with a removable and non-reliable server. Int. Trans. Operat. Res., 9: 195-212. 